\title{
Nursing process in the everyday life of nurses in Psycho-Social Attention Centers
}

\author{
Processo de Enfermagem no cotidiano do enfermeiro nos Centros de Atenção Psicossocial \\ Proceso de enfermería en rutina del enfermero en los Centros de Atención Psicosocial
}

\author{
Paula Fernanda Lopes ${ }^{1}$, Ana Paula Rigon Francischetti Garcia ${ }^{1}$, Vanessa Pellegrino Toledo ${ }^{1}$
}

This study aimed at understanding the achievement of Nursing process in the everyday life of the nurse in Psychosocial Attention Centers. This was a qualitative study, including data collected by means of semi-structured interviews, from April to May 2012, in Campinas, São Paulo, Brazil, with nine nurses. From the data analysis, three thematic categories arouse: the Nursing process understood as assistance systematization; the difference in the nursing work process in the different mental health equipment; and the dichotomy between body and mind. The Nursing process is carried out as performance of the data collection instrument. The lack of clarity of the nursing role in the multi-professional team is an obstacle to the elaboration of an individual therapeutic project, resulting in difficulties to incorporate the concept of integrality and therapeutic interpersonal relationship for the preparation of the Nursing process.

Descriptors: Nursing; Nursing Process; Psychiatric Nursing; Mental Health.

Objetivou-se compreender a realização do processo de Enfermagem no cotidiano do enfermeiro que atua em Centros de Atenção Psicossocial. Estudo qualitativo com dados coletados por meio de entrevistas semiestruturadas, realizadas de abril a maio de 2012 em Campinas, SP, Brasil com nove enfermeiros. Da análise dos dados, emergiram três categorias temáticas: o processo de Enfermagem entendido como sistematização da assistência, a diferença do processo de trabalho do enfermeiro nos distintos equipamentos de saúde mental, e a dicotomia entre corpo e mente. 0 processo de Enfermagem é realizado como preenchimento do instrumento de coleta de dados. A falta de clareza do papel do enfermeiro na equipe multiprofissional é um obstáculo para a elaboração do projeto terapêutico individual, ocasionando dificuldade na incorporação do conceito de integralidade e no estabelecimento da relação interpessoal terapêutica, para elaboração do processo de Enfermagem.

Descritores: Enfermagem; Processos de Enfermagem; Enfermagem Psiquiátrica; Saúde Mental.

El objetivo fue comprender la aplicación del proceso de Enfermería en rutina del enfermero en Centros de Atención Psicosocial. Estudio cualitativo, con los datos recogidos a través de entrevistas semiestructuradas, realizadas entre abril y mayo de 2012, en Campinas, SP, Brasil, con nueve enfermeros. Del análisis de los datos, emergieron tres categorías temáticas: el proceso de Enfermería entendido como sistematización de la atención; la diferencia del proceso de trabajo del enfermero en los varios equipamientos de salud mental; y la dicotomía entre cuerpo y mente. El proceso de Enfermería se realiza al llenar el instrumento de recolección de datos. La falta de claridad sobre el papel del enfermero en el equipo multidisciplinario es un obstáculo para el desarrollo del proyecto terapéutico individual, resultándose en dificultades en la incorporación del concepto de integralidad y en el establecimiento de la relación interpersonal terapéutica para elaboración del proceso de Enfermería.

Descriptores: Enfermería; Procesos de Enfermería; Enfermería Psiquiátrica; Salud Mental.



Corresponding author: Vanessa Pellegrino Toledo

Rua Tessália Vieira Camargo, 126 - Cidade Universitária Zeferino Vaz. Caixa Postal 6111 CEP: 13083-970. Campinas, SP, Brazil. E-mail: vtoledo@fcm.unicamp.br
} 


\section{Introduction}

At present, it is necessary to nurses who work in the mental health field, recognizing the various dimensions of mental illness perception, so that it can be established new forms of care involving practices aimed at humanized and singular attention.

With the anti-asylum movement and the deinstitutionalization, the need to implement mental health actions, producing different possibilities of care arouse. To achieve the goal of Psychiatric Reform, including the recovery of citizenship of people with mental disorders, the structure of the health care network in mental health becomes necessary, it should promote community life and the autonomy of users by including them in its territory ${ }^{(1)}$.

The mental health network can be consisted of several assistance devices that allow the psychosocial care to users with mental disorders, with the Psychosocial Care Centers organization, which should seek stronger ties between the field of mental health and the community, providing support in mental health primary care and giving support to the crisis, involving not only medical treatment, but an understanding of the situation that surrounds it, with interventions whose goal is to ensure their reintegration in the social context and family ${ }^{(2)}$. Thus, we propose a care that has as premises integrated care and humanization of care.

Intervening in this new model of mental health care, as proposed by the Psychiatric Reform, it is important for nurses to build a new position, moving the historically attributed and assumed lookout and repressor to a position of therapeutic agent. This position implies a care that transcends the host with food, clothing and medication guarantees ${ }^{(3)}$.

Consequently, it is considerate the emphasis on the emotional competence of nurses, characterized by the ability to live with the pain of others, developing empathy. In that way, understanding the other from its own reference system allows nurses to evolve into an active therapist role in the individual dynamics, which produces an environment and a therapeutic relationship as a strategy for resolving the crisis $^{(4-5)}$.

The interpersonal relationship considers the person and the experiences in their uniqueness, being considered by many researchers as the centerpiece for the practice of Mental Health Nursing, and becoming crucial to good therapeutic results. From the interaction and the interventions proposed by the nurse, the patient can get positive results, promoted by changes and the personal growth ${ }^{(6)}$.

The interpersonal relationship between the nurse and the patient became central to the current practice. This relationship requires investment of both sides and faces the challenge of establishing and maintaining a professional, respectful and therapeutic relationship, promoting the recovery ${ }^{(6)}$. We emphasize its importance, because the nurse-patient connection becomes the background for the first to make the Nursing process, organizing and directing the $\operatorname{care}^{(7)}$.

The nurse who uses interpersonal relationships to develop the Nursing process can conduct consultations, which focuses extends beyond biological aspects, aiming to Nursing diagnoses and a care plan that influences the adoption of practices favourable to patient's health ${ }^{(6-8)}$.

Whereas the Psychiatric Reform proposes innovative ways to care for, and that its meaning is the production of therapeutic effects, which should prioritize the comprehensive care and the autonomy of the subject, the nurse has alternatively the Nursing process that is based on recognition of the patient's life history, since this profession is based in the residence, not in the visit. This way, the nurse prepares the care over their clinical practice. To do so, the creation of care devices becomes necessary to nurture the information produced by the therapeutic relationship ${ }^{(3)}$.

The study highlights the importance of recognizing the clinical practice established by nurses in Psychosocial Care Centers, different from that working as a repressor agent, building a therapeutic approach, developed from theoretical and ethical 
principles aimed at humanized and singular attention that corroborates to the process of Nursing.

The objective of this study is thereby, to understand the performance of Nursing process in the nurse's routine that works in the Psychosocial Care Centers.

\section{Method}

Qualitative study, exploratory and descriptive, developed in the southwest of the city of Campinas (São Paulo) with nurses working in two Psychosocial Care Centers, and the city has 1,123,241 inhabitants. The city opted for the districting, which is the progressive decentralization of planning and health management, and is organized according to the principles and guidelines of the National Health System, being decentralized in five $\operatorname{districts}^{(9)}$. The selection of this health district was given for convenience, since there were activities of the theoretical and practical disciplines from the mental health field of the Undergraduate Program in Nursing at the State University of Campinas.

There were nine respondents from a total of eleven nurses, because two were away in the period of data collection. The study took place in April and May 2012.

For data collection we used semi-structured interviews conducted in private atmosphere, being recorded and further processed. To guide the data collection a guiding question was used: How is it for you to make the Nursing process in Psychosocial Care Center?

The interviews were transcribed and analyzed using the analysis of content, following the steps: (1) pre-analysis, through which there was the brief reading of speeches; (2) exploration of the material, allowing the classification and codification of recording units, listing the units of meaning; and (3) the treatment of the results, phase in which were added and prioritized categories of greater relevance for the subject matter to be discussed and interpreted in accordance with the theoretical framework ${ }^{(10)}$.

The abstracted categories were: 1) Process of Nursing and systematization of nursing care: complementary or synonyms? 2) Work process and nursing process.

This study was approved by the Ethics Committee of the Faculty of Medical Sciences, from the State University of Campinas, respecting the principles of Resolution 96/96, in the Opinion 1179/2011. The participants signed a consent form.

\section{Results}

The age of participants ranged from 20 to 40 years, and the working time at the study site was characterized by: three nurses with less than a year of work and six between one and five years, being five female and four male.

\section{Category 1 - Process of Nursing and systematiza- tion of nursing care: complement or synonyms?}

The findings in this category indicated that the Nursing process was conceived by nurses as systematization of nursing care, as it is evidenced in the following statements: The Nursing process is made here to the bed night, for patients who are on a whole hospitalization (E9). The process of Nursing, from what I understand, is much involved with working with the systematization of nursing care (E6).

It was evident that the Nursing process was carried out only for patients submitted to full hospitalization, which means that, those requiring 24 hours attention, as noted in the following lines: $A$ patient was in bed; we performed a Nursing process, the systematization of Nursing care (E8). The Nursing process is made here to the night bed (E6).

In this study, nurses cited a lack of professional training as difficult to perform the Nursing process: in the college we cannot have a specific subject concerning mental health (E9). In mental health this is very new, there are not many studies yet (E2).

Another difficulty was represented by the routine on the Psychosocial Care Centers, with a large 
number of patients, which happens because it is an open and community service of the Unified Health System, as evidenced in the following statements: I cannot organize myself, there is a vast demand, because we work with "open doors" and there are people knocking on the door all the time to be helped (E8). The number of patients that spend the day here is also too large (E9).

\section{Category 2 - Working process and Nursing process}

In this category, nurses conceived the Nursing process as the work process, pointing differences between the way it is done in the clinical hospital and the Psychosocial Care Center, according to the following statements: The process ends up working a little different from the hospital, quite different from the hospital, which is very hard, but it works (E5). In the hospital it is also individual, but here is very different, because the issue we will take into account in here is the mental, the behaviour, the relations (E1).

In the statements below, you can also identify that professionals refer to the difficulties of working in multidisciplinary team: Sometimes there is an intervention or a change in the care plan made by another professional who sometimes has no competence to do it (E9). So sometimes the intervention of psychologists, of the Occupational Therapist hinders a little the Nursing process (E8).

This study also revealed the difficulty of nurses to identify their role, differentiating it from other team members: When I first came here I found a little odd not having a clear separation between who is the nurse and who is the psychologist (E4).

\section{Category 3 - Dichotomy of body and mind and its implications for the Nursing process}

This category referred to a dichotomy between the attention to the biological body and the psychological care, as evidenced by the following statements: Our biggest problem here, in the Psychosocial Care Center, is our look at the mental state examination and rather forgetting clinical cases of the patients (E8). The clinical question is also evaluated, but it is not what stands out (E6).
The fragmentation between body and mind can be seen in the statements that point to the difference between the Nursing process developed in a hospital and in the Psychosocial Care Center, reaffirming its conception as a technical action: Because in the hospital, when the patient is here and that's it (E5). In the hospital is easier: the patient has an inflammation or swelling, do like this, do like that (E1).

\section{Discussion}

The Nursing process, when understood by the nurses of Psychosocial Care Centers as a synonym of systematization of nursing care, it may become more a technical action, static, and not the essence of the nursing practice, which requires theoretical knowledge, practical experience and intellectual ability besides indicating a set of actions performed against the judgment on the patient, family or human community needs at any given time of the healthdisease process ${ }^{(11-12)}$.

In contrast, the systematization of nursing care contributes to organize care, making possible the operation of its process and in this way giving visibility to its contribution under health care in any environment in which professional practice occurs, or in institutions providing hospitalization services or ambulatory services, schools, community associations, factories, homes, among others ${ }^{(12)}$. Thereby, the systematization of nursing care organizes professional work making possible the implementation of the Nursing process; are complements and not perfect synonyms ${ }^{(12)}$.

The study participants understood the Nursing process as a technical action, not being developed with all patients in the service, prioritizing only those who are on a full hospitalization. They completed forms to systematize the nursing care without developing the following stages, since they have associated the Nursing process exclusively to data collection instrument, minimizing the relationship between care and its theoretical framework. The Nursing process goes beyond collecting information or filling out 
forms, taking continuity with the identification of the patient's needs, with the results to be obtained and the nursing interventions to be applied ${ }^{(13)}$.

The fact that the care was not be perceived as a process, but as a task, is historical ${ }^{(14)}$. The bases of professional work with the advent of modern Nursing and the contribution of Florence Nightingale were focused on regulatory aspects ${ }^{(14)}$. The care was conceived as the treat of the disease and the individual, object of the care, was isolated, reduced to parcels and excluded from social and collective dimensions ${ }^{(14)}$. The history of this profession follows a legacy of alienation, to which was submitted, having its work process characterized by the repetition of fixed tasks, denying therefore the nurses' interaction and awareness of their role based on scientific knowledge ${ }^{(15)}$.

It cannot be overlooked the importance of hospital and outside hospitals techniques, which are indispensable for the maintenance of life and to promote the return of the physical condition. However, there is an overvaluation of the technique, which alienates the nurses' investment required for a care that goes beyond the biological aspects, organized by the interpersonal relationship ${ }^{(6,15)}$. Such organization overcomes the challenges that are faced in clinical nursing practice and promotes a gathering movement, which is opposed to the abstract duty and limiting the performance of a task.

The difficulty in recognizing the difference between the Nursing process and the systematization of nursing assistance can be the lack of professional training, once the teaching of Nursing currently presents difficulties of matching the theoretical and practical content to the care reality ${ }^{(16)}$. This happens because, even today, even after the Psychiatric Reform, the theoretical approach of the majority of Undergraduate Nursing Programs in Brazil are based on the psychopathological manifestations, in order to prepare the student to act in accordance with the practice of clinical psychiatry, in which the disease is understood exclusively as a set of symptoms that require interventions to achieve a state of mental balance and not as a whole being in need of psychosocial care ${ }^{(16)}$.

This fact is also observed in other countries where education is not conducive to self-knowledge, a fundamental step for nurses to develop empathic capacity, because it is not considered as part of the training the reading of anxiety and conflicts that arise in the practice of therapeutic relationship ${ }^{(4-5)}$.

The second challenge is the organization of the network of mental health care after the Psychiatric Reform, which dismantled the asylum apparatus, based on involuntary admissions, and structuring the mental health care in the community, through the Psychosocial Care Centers with a focus on psychosocial rehabilitation, resulting in increased demand ${ }^{(17)}$. The Nursing process can be a method that favours the integral care, considering the subject, his family and the context in which they live, which can increase the production of existential spaces in society ${ }^{(11,17)}$.

Despite the psychosocial rehabilitation perception, in this study, it was found that the routine of everyday life ends up triggering actions used in psychiatric hospitals, as the medicalization of social, producing static effects, resulting in the idea that the Psychosocial Care Center is an incarceration place outside of the old asylum walls ${ }^{(16-17)}$.

However, the process of nursing, allied to the principles of psychosocial rehabilitation, can promote flexibilities in the management of individuals, in the community context, as it considers the uniqueness in $\operatorname{care}^{(17)}$.

In this study, nurses conceived the Nursing process as the process of work, pointing differences between the way it was done in the hospital and in the Psychosocial Care Center. This difference can be explained because in both devices, there are different work processes. It the hospital, although there is the multidisciplinary work, the medical hegemony prevails, with centralization of power and subservience of the other members of the health team ${ }^{(18)}$. In the Psychosocial Care Centers, the multidisciplinary team aims to overcome the asylum 
model of medical exclusive, favouring the interaction with the various professionals, and developing practical or appropriate therapeutic techniques to deal with the cases, with the agreement of all on the patient's therapeutic relationship project ${ }^{(19)}$.

While the process of working in hospitals is characterized by hierarchical imposition, individualized activity and separation between employee/product, worker/meaning and object of work in the Psychosocial Care Center is different ${ }^{(19)}$. Due to the complexity of the object, the subject who suffers and was not been evicted from its social context redirects the organizational logic of the services and the labour process, turning to intensive care and reappropriation of relations with the city and citizenship, developing teamwork in interdisciplinary and more horizontal dynamic, allowing the collective creation of the work process ${ }^{(19) .}$

Interdisciplinarity emerges as a real need for the realization and resolution of psychosocial rehabilitation services, helping professionals not to lose the notion of whole, essential to build bridges that allow qualitative leaps in health care management. In this sense, the interaction between various disciplines provides mutual enrichment ${ }^{(20)}$.

Nevertheless, taking up the issue of lack of preparation, many professionals still receive an education marked by the medical-biological paradigm, which may point to the lack of preparation for interdisciplinary work ${ }^{(18)}$. In this type of work, professionals must continue to undertake actions of their own, and also implement those that are common to all, involving the use of different strategies and the integration of different knowledge ${ }^{(20)}$.

From the articulation of individual knowledge of each professional, it is up to the team to build a unique treatment plan for the patient, in other words, a set of therapeutic procedures articulated proposals for an individual or collective subject, the result of collective discussion of an interdisciplinary team with matrix support if necessary(21).

Assisting people in mental distress is a complex action, which means that nurses can use the Nursing process as a singular contribution to the therapeutic $\operatorname{project}^{(7)}$.

It is important that these activities are developed with patients in a creative and interdisciplinary way, individualizing care to the user, because otherwise they would be going against the principles of the Psychiatric Reform, as provided by Law $10.216 / 2001$, known as the Antimanicomial Law or Law of the Psychiatric Reform, which transfers hospital treatment for a network of psychosocial care, ensuring effective respect for the rights and dignity of the person with mental disorders ${ }^{(20)}$.

It is noteworthy that the integrality is a principle for the constitution of psychosocial care network. It is therefore considered that the separation of body and mind care is a serious problem for the improvement of services ${ }^{(2,22)}$. People with mental disorders have reduced life expectancy by 20 years and two to three times more mortality risk compared to the general population. The most common cause of death is biological problems, due to the negligence of these in patients with mental disorders. Nurses, as professionals involved with these patients should be aware of this ${ }^{(22)}$.

As found in the interviews, studies show that mental health care nurses still have doubts whether or not to provide this biological care for patients with mental disorders ${ }^{(22)}$.

Although the findings indicate a separation of body and mind by respondent nurses, psychosocial rehabilitation seeks to restore the subjectivity of the individual, enabling it to subvert the process of confinement, restoring their autonomy in society ${ }^{(17)}$. For this to occur, the mental disorder is considered as an extra data in the individual's life history which is seen as a person living in a territory that maintains social and emotional relationships, and that is part of a particular family - as well showing a mental disorder that affects differently in their daily lives ${ }^{(23)}$.

Once again, the literature justifies as a cause of this fragmented care, the technicist education of 
nurses, whose references are the diagnosis, treatment and prognosis, without these being integrated to the health needs of individuals and populations, the sectoral management and social health control ${ }^{(23)}$.

This fragmentation goes against one of the principles of the Public Health System: the comprehensiveness, understood as an articulated and continuous set of actions and preventive and curative services, individual and collective, required for each case in all levels of complexity in the system ${ }^{(24)}$.

Currently, the nurse should organize the Nursing process based in comprehensive health care, in a more flexible and creative perspective, envisioning a complex and unique care, considering the person with a psychiatric disorder as a subject in its totality ${ }^{(18)}$.

The concept of comprehensive care is the recognition that each person is an indivisible and social whole, that the actions of health promotion and recovery cannot be fragmented ${ }^{(18)}$. These ideas corroborate the psychosocial model, which focuses on the interactions between professionals and users of health services, with the predominance of horizontal relationships, so that both can star in the rehabilitation $\operatorname{process}^{(18)}$.

To make this happen, it is important that nurses consider the link between biological, psychological and social perspectives, as their contribution to the therapeutic project deals with the interpersonal relationships, supporting the Nursing process. This relationship promotes the self-knowledge by the patient ${ }^{(4)}$, so it can create skills to solve their problems that are effects of the dichotomy between body, mind and society. To insist in that division is to oppose to the principle of integrity and principles of psychosocial rehabilitation $^{(18)}$.

\section{Conclusion}

This study enabled an expansion of understanding the completion of the Nursing process in the Psychosocial Care Centers of the southwest region of Campinas, understood as systematization of nursing assistance. It is noticed that nurses minimize the care to the execution of a task, in other words, the completion of a data collection instrument; overvalue the technique, alienating from integrated care that can be obtained through the interpersonal relationship. Furthermore, they point to the lack of professional training, the large number of patients and the service routine as difficulties in carrying out the process of Nursing.

Nurses also showed lack of clarity about the Nursing process in relation to the work process. Differences were identified between working in the hospital and in the Psychosocial Care Center, highlighting the need for teamwork and the difficulty of nurses to understand their role in this context.

From the articulation of the professionals' knowledge in the Psychosocial Care Center, a therapeutic project for a patient is built, and the contribution of nurses is precisely in the Nursing process.

The difficulty to understand their work limits the understanding of the patient's suffering, dichotomizing care and so opposing to the psychosocial rehabilitation. This fragmentation is related to nursing education based on the biomedical model, which minimizes the importance of establishing a therapeutic relationship with the patient. Acting this way, contradicts to one of the principles of the Unified Health System, when performing the Nursing process excluding the perception of integrality.

Recognizing the implications of the conjunction body, mind and society in the development of care, the Nursing process, learned and developed as a way to collaborate with the individual treatment plan, can be taken as the contribution of nurses in these new facilities.

It is noteworthy that the increase of production on this issue and the training of nurses can bring benefits not only to the work in the Psychosocial Care Center, but also to the network of psychosocial care, recognizing that the care context in mental health transcends a single device. 


\section{Collaborations}

Lopes PF contributed to the design, collection of field data, analysis, data interpretation and writing of the article. Garcia APRF and Toledo VP contributed to the design and final approval of the version to be published.

\section{References}

1. Schneider ARS. A rede de atenção em saúde mental: a importância da interação entre a atenção primária e os serviços de saúde mental. Rev Ciênc Saúde. 2009; 2(2):78-84.

2. Ministério da Saúde (BR). Relatório de Gestão 2007-2010: Saúde Mental no SUS: as novas fronteiras da Reforma Psiquiátrica. Brasília: Ministério da Saúde; 2011.

3. Kirschbaum DIR. Concepções produzidas pelos agentes de enfermagem sobre o trabalho em saúde mental com sujeitos psicóticos em um centro de atenção psicossocial. Rev Latino-am Enfermagem. 2009; 17(3):368-73.

4. Loyola CM, Rocha RM. Compreensão e crítica para uma clínica de enfermagem psiquiátrica. Cad IPUB. 2000; 19(1):7-10.

5. Rosenberg R, Rogers C. A pessoa como centro. São Paulo: EPU; 1977.

6. McKenna L, Boyle M, Brown $\mathrm{T}$, Williams B, Molloy A, Lewis B, et al. Levels of empathy in undergraduate nursing students. Int J Nurs Pract. 2012; 18(3):246-51.

7. Wright KM. Therapeutic relationship: Developing a new understanding for nurses and care workers within an eating disorder unit. Int J Ment Health Nurs. 2010; 19(3):154-61.

8. Duran ECM, Toledo VP. Análise da produção do conhecimento em processo de enfermagem: estudo exploratório-descritivo. Rev Gaúcha Enferm. 2011; 32(2):234-40.

9. Secretaria de Economia e Planejamento. Fundação Sistema Estadual de Análise de Dados. Perfil Municipal de Campinas [Internet]. 2014 [citado 2014 nov 10]. Disponível em: http://www.seade. sp.gov.br/produtos/perfil/perfil.php
10. Bardin L. Análise de conteúdo. Lisboa: Edições 70; 2011.

11. Dias CB, Aranha e Silva AL. The profile and professional practice of nurses in a psychosocial care services. Rev Esc Enferm USP. 2010; 44(2):469-75.

12. Malucelli A, Otemaier KR, Bonnet M, Cubas MR, Garcia, TR. Sistema de informação para apoio à Sistematização da Assistência de Enfermagem. Rev Bras Enferm. 2010; 63(4):629-36.

13. Codogno L, Toledo VP, Duran ECM. Consulta de enfermagem e hipertensão arterial na estratégia saúde da família: proposta de instrumento. Rev Rene. 2011; 12 (n.esp.):1059-65.

14. Mulato SC. Enfermagem tradicional, atual e do futuro: a visão de docentes de enfermagem. Rev Enferm UERJ. 2010; 18(4):572-7.

15. Pokorski S, Moraes MA, Chiarelli R, Costanzi AP, Rabelo ER. Nursing process: from literature to practice. What are we actually doing? Rev Latinoam Enfermagem. 2009; 17(3):302-7.

16. Soares AN, Silveira BV, Reinaldo AMS. Serviços de saúde mental e sua relação com a formação do enfermeiro. Rev Rene. 2010; 11(3):47-56.

17. Pinto ATM, Ferreira AAL. Problematizando a reforma psiquiátrica brasileira: a genealogia da reabilitação psicossocial. Psicol Estud. 2010; 15(1):27-34.

18. Duarte MLC, Olschowsky A. Actions of nurses in a psychiatric hospitalization unit at a university hospital. Rev Bras Enferm. 2011; 64(4):698-703.

19. Sampaio JJC, Guimarães JMX, Carneiro C, Filho CG. Working in mental health services in the context of Brazilian psychiatric reform: a technical, political and ethical challenge. Ciênc Saúde Coletiva. 2011; 16(12):4685-94.

20. Schneider JF, Souza JP, Nasi C, Camatta MW, Machineski GG. Concepção de uma equipe de saúde mental sobre interdisciplinaridade. Rev Gaúcha Enferm. 2009; 30(3):397-405.

21. Pasche DF, Passos E, Hennington EA. Cinco anos da política nacional de humanização: trajetória de uma política pública. Cienc Saude Coletiva. 2011; 16(11):4541-8. 
22. Happel B, Scott D, Platania-Phung C, Nankivell J. Should we or shouldn't we? Mental health nurses' views on physical health care of mental health consumers. Int J Ment Health Nurs. 2012; 21(3):202-10.
23. Mielke FB, Kantorski LP, Olschowsky A, Jardim VMR. Características do cuidado em saúde mental em um CAPS na perspectiva dos profissionais. Trab Educ Saúde. 2011; 9(2):265-76.

24. Paim JS, Silva LMV. Universalidade, integralidade, equidade e SUS. Bol Inst Saúde. 2010; 12(2):10914. 